\title{
DAHP Expected Utility Based Evaluation Model for Management Performance on Interior Environmental Decoration - An Example in Taiwan
}

\author{
Yu-Lung Chen ${ }^{1}$, Ai-Chih Cheng ${ }^{2}$, Sung-Lin Hsueh ${ }^{2}$, Danji Qu ${ }^{2 \star}$ \\ ${ }^{1}$ Department of Civil Engineering, National Kaohsiung University of Applied Sciences, Kaohsiung, TAIWAN \\ ${ }^{2}$ Graduate Institute of Cultural and Creative Design, TungFang Design University, TAIWAN
}

Received 25 May 2017 • Revised 14 September 2017 • Accepted 12 October 2017

\begin{abstract}
Construction industry has been criticized as the industry producing high pollution. Especially, a newly built house is often torn down and renovated the walls in the interior space at the life cycle stage of a housing project when buyers are using and maintaining, due to distinct customer demand and preference. Structural walls and beam columns are even randomly drilled for the piping requirement of air conditioner pipelines to result in public danger. It could be attributed to the regulation of interior environmental decoration without safety check in Taiwan and some interior designers, in order to strive for cases in the high competition, corresponding to customers' demands for changing interior patterns. In addition to newly built houses, the sale and transfer of second-hand houses is another thought for the renovation work of interior space environmental decoration to disturb the life of neighbors and seriously damage the environment. Accordingly, Delphi method, Analytical hierarchy process, and Utility theory are applied in this study to establish an AHP expected utility based evaluation model for management performance on interior environmental decoration, aiming to provide the safety management for interior environmental decoration and reduce the management review for energy consumption and environmental protection.
\end{abstract}

Keywords: high pollution, highly competitive, Delphi method, Analytical hierarchy process, expected utility

\section{INTRODUCTION}

Except for residence, houses are important investment goods in Taiwan. Under the social climate of investment hype, housing projects are constantly developed in cities where the goods are easily sold and realized. Besides, the abuse of collusion between businessmen and government officials and the failure of supervisory mechanism of urban planning and management have pseudo public interests become the tactics to cover illegal development for urban consolidation and housing projects corresponding to corporations. It not only worsens the usage load of urban public facilities but also results in serious traffic congestion, air pollution, and noise pollution as well as ruralurban development divide and serious Heat Island Effect (Levermore and Parkinson, 2016). By observing dense urban environments around the world, Fokaides et al. (2016) indicated that large sealed surfaces were extensively reported to induce higher surface temperatures. Since Taiwan has subtropical climate, it is extremely hot in summer. Heat Island Effect would cause high discomfort in daily life that summer is the peak period for electricity consumption in cities. It requires numerous air-conditioners for maintaining the normal life in distinct interior space that increases the cooling load on urban buildings (Akasaka et al., 2002). Moreover, power consumption and heat discharge in interior space are also increased to worsen urban Heat Island Effect and result in the vicious cycle of high temperature being constantly created.

Under the drive of highly economic growth, the per capita income in developing countries is continuously enhanced and the population is moving towards cities to results in impact on complex environments, such as

(C) Authors. Terms and conditions of Creative Commons Attribution 4.0 International (CC BY 4.0) apply. 


\section{Contribution of this paper to the literature}

- Interior decoration regulations with both award and punishment could help guide private housing to the benign development of interior environmental decoration.

- Interior designers' environmental protection awareness and the relative award and punishment should be promoted.

inadequate housing, schools, transportation, public facilities, medical treatment, and parks and green space and more serious environmental pollution problems. Lakshmana (2014) pointed out the consequence of the complex contours of urban growth in terms of area, population and households on environment. A part of it was the significant contribution of the exhaust emission of automobiles and motorcycles to urban air pollution, as home and transport energy use were especially related to sociodemographic variables like income and household size (Poortinga et al., 2004). Moreover, urban public construction, development of housing projects, and interior space environmental decoration work would cause compound pollution, such as air pollution, noise pollution, and waste pollution, in urban environments. Such problems would further involve in the clean-up and management problems of recycling, landfill, and burning of construction waste (Kucukvar et al., 2014) to result in the load of personnel expenses, waste treatment, and the maintenance of averse space on management departments.

According to the statistics of total greenhouse gas emission of Environmental Protection Administration, the annual growth rate of housing departments was ranked the second, next to traffic departments (Taiwan Environmental Protection Administration, 2017). According to the statistics, the seriousness of pollution emitted from home life could be understood; meanwhile, families with higher income would produce more diversified substance pollution in the home life. In this case, families should be regarded as primary pollution management targets in cities to properly control pollution emitted from families. In order to effectively reduce pollution from home life, the nature of the pollutant should be recognized to achieve the objectives of management and control (Plassmann and Khanna, 2006). Furthermore, urban houses are the critical investment goods for real estate investors, and the cultivation of investment in housing goods is often by cultivating individual investments in the home by way of interior design and decoration practices (Jacobs and Cairns, 2008). Housing projects, except for residence, have become the hype of investment goods to result in the multiple development difficulties and loads due to the concentration of population on cities. What is more, the frequent sale and transfer of housing goods and the environmental decoration work in interior space are important roots of urban pollution which have been ignored. Besides, the lack of strict regulations on the environmental decoration work in interior space results in the management loophole in construction industry. In addition to the problems of air pollution, noise pollution, and waste pollution, there are serious safety incidents caused by tearing down structural walls for increasing the space.

From above connotation, it is realized that the environmental decoration in interior space is the source of pollution which could easily be neglected by regulations. Various pollution problems should be emphasized and solved for the overall environmental protection and management. For instance, Bluyssen et al. (2010), aiming at the improvement of interior air quality, proposed to start from education and awareness as well as regulations and policies. In order to solve the pollution problem caused by environmental decoration in interior space, Delphi method, Analytical hierarchy process (AHP), and Utility theory are applied in this study to propose an evaluation model for management performance on interior green environmental decoration for reducing pollution. It aims to provide customers and designers with the evaluation to construct high-quality and healthy interior space and to understand the management performance on reducing the pollution from interior environmental decoration.

\section{LITERATURE REVIEW}

Climate disasters and influence on biodiversity resulted from high greenhouse gas emission, greenhouse effect, climate anomaly, and climate change have been the common concern globally. Although economy-oriented people do not agree with the direct correlation between greenhouse gas pollution and climate change, the pollution emission from life and industries in China, where industries and businesses are actively developed, has seriously resulted in air pollution. Besides, haze-fog pollution has become one of the major atmospheric pollution problems in China (Li et al., 2016). Meanwhile, the economic boom and the increase in national income have also resulted in environmental pollution and damage. Hsueh (2012) indicated that the high greenhouse gas emission to the environment was rooted from people's desire for material needs. The habit of low-carbon life could be effectively enhanced in societies merely when individuals, families, and enterprises stressed on social responsibility (Hsueh, 2015).

Population concentrating on cities has resulted in traffic congestion, pollution from automobiles and motorcycles emitting exhaust, high-density housing buildings, exhaust emitted from life, and multiple pollution from interior environmental decoration work. Besides, high-density housing could easily result in difficulties in urban planning. To solve urban planning, Novakowski and Wellar (2009) indicated that the Delphi technique could 


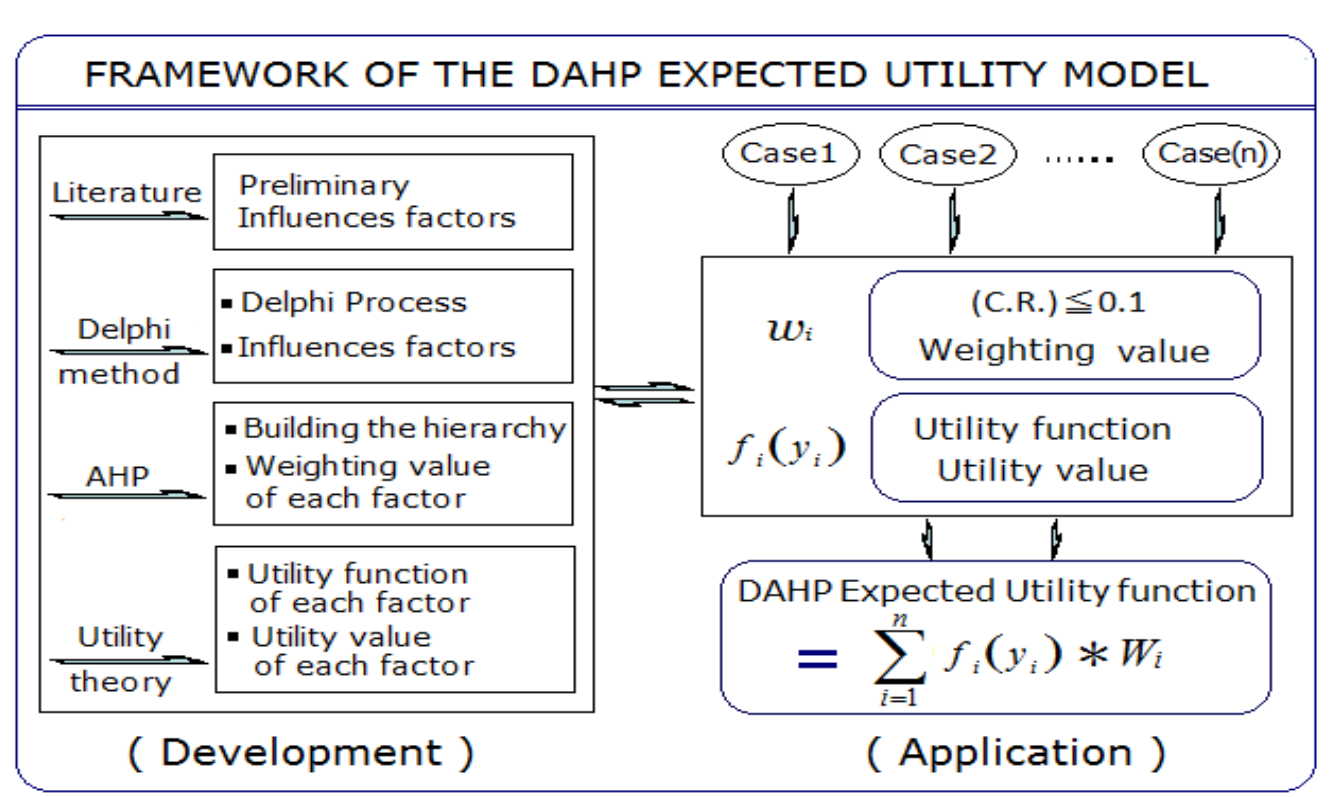

Figure 1. DAHP Expected Utility Based Evaluation Model Architecture

contribute to making informed choices in a wide variety of decision and policy environments when metropolitan areas continuously confronted a growing number of increasingly difficult planning issues. The Delphi technique presents the function of group decision-making, where the optimal key factors in urban planning could be acquired through the assistance of industry experts, senior specialists in governmental management departments, and senior researchers. The further combination of the governance of smart city and the data collection with Big-Data could assist in various planning of a perfect city and distinct management and pollution control.

Being a major urban pollution, interior environmental decoration work should be concerned. This study therefore aims to discuss the decision-making model for solving interior space pollution. Relevant factors in interior green environmental decoration are first organized in the modeling process. It is regarded as the primary measure to develop an evaluation model. Since there are plenty of factors in the pollution caused by interior environmental decoration work, it could result in the normal pollution in the use of housing space when improper planning and design are included. Designers' professional competence and house owners' concepts therefore play the role to influence the design. Designers with green energy design competence and house owners presenting agreement with low-carbon life are the key factors in getting rid of pollution from interior environmental decoration. Air pollution and noise pollution from construction equipment (Sellappan and Janakiraman, 2014), pollution from building materials with chemical toxicant (Gerber and Yacoubian, 2002), and textiles building material pollution (White and Kuehl, 2002) are the common pollution in the interior environmental decoration of houses and the use process. Zheng et al. (2011) pointed out the factors of ventilation performance, temperature, humidity, and interior pollution (Ojeda-Benítez et al., 2013); and, Lee and Levermore (2012) indicated that loft and wall insulation decreased internal air temperatures by up to $17 \%$ and low e glazing with louvres by up to $8 \%$.

By summing up above connotation, the factors in interior low-pollution environmental decoration could be divided into three dimensions of designers' professional competence and house owners' concepts, pollution in decoration process, and use comfort. The factors in each dimension are described as below.

(1) Designers' professional competence and house owners' concepts: green energy design experience, habit of low-carbon life, and social responsibility for the agreement with environmental protection.

(2) Pollution in decoration process: air pollution, noise pollution from construction equipment, construction waste pollution, pollution from building materials with chemical toxicant, and textiles building material pollution.

(3) Use comfort: ventilation performance, environmental building materials, loft and wall insulation.

\section{RESEARCH METHOD AND RESEARCH DESIGN}

Delphi method, Analytic Hierarchy Process, and Utility theory are applied in this study to establish the DAHP expected utility based evaluation model. Meanwhile, the qualitative analysis and quantitative analysis function of the three approaches are integrated to play strict roles at different stages of modeling. The overall research architecture is shown in Figure 1. 
From the DAHP expected utility based evaluation model architecture, the entire evaluation model is divided into model development and application. Model development contains five steps of (1) preliminary factors organized from literatures, (2) factors required for Delphi experts confirming the modeling, (3) calculation of relative weights of factors in AHP, (4) conformation and calculation of the utility function of factors, and (5) completion of DAHP expected utility function. Furthermore, model application covers four steps of (1) calculation of relative weights of factors, (2) calculation of the utility value of factors, (3) calculation of the overall expected utility value with DAHP expected utility function, and (4) performance evaluation of a single case or performance comparison among several cases. The DAHP expected utility based evaluation model is a decision-making analysis model developed by integrating Delphi method, Analytic Hierarchy Process, and Utility theory that it presents the qualitative analysis and quantitative analysis functions. Such three approaches develop the functions and characteristics of model combination at different stages in the modeling process.

Delphi method and research design. Delphi method is a pragmatic research method created in the 1950s by researchers at the RAND Corporation for the use in policy making (Brady, 2015) and is broadly promoted and applied to various fields, such as Technique in Normative Planning Research (Novakowski and Wellar, 2009), Health Care Service Effectiveness (Escaron et al., 2016), and Protected Area Co-Management Capacity Building Programme (De Urioste-Stone et al., 2006). As Delphi method presents the advantage of anonymous decisionmaking from experts in industries, government, and universities, it is applied at the modeling stage. In regard to the invitation of Delphi experts, 10 professional interior designers with more than 15 -year practical experiences, 8 senior specialists in public sectors, and 7 senior professors in colleges are invited. The group decision-making skill of Delphi experts is further utilized for confirming the factors required for establishing the evaluation model. The Delphi questionnaire survey is applied anonymously to acquire each expert's opinion data.

The dimensions and factors in interior low-pollution environmental decoration organized in the previous chapter are the reference for designing the Delphi questionnaire survey. The Delphi questionnaire survey is preceded through post, direct interview, or interview through telephone. It takes about three and a half months and goes through three times of Delphi questionnaire survey to acquire the consistent agreement of Delphi experts for the revision of dimensions and factors. The revised dimensions and factors are organized as following.

(1) Factors in designers and house owners: agreement with energy-saving design, pro-environment, and social responsibility.

(2) Factors in decoration management: pollution management, waste management, and new construction technology.

(3) Factors in residence comfort: ventilation design, thermal insulation of walls, and green building material.

AHP and research design. Analytic hierarchy process (AHP), proposed by T.L. Satty, is a multi-attribute quantitative decision-making analysis tool, and the methodology is broadly applied to the practice and academic research on management. The research application covers diverse fields, e.g. Model for Measuring Korean Administrative Corruption (Yun, 2004), Approach to Convention Site Selection (Chen, 2006), New Product Development (Battistoni et al., 2013), and Comparing innovation across regions (Liefner and Jessberger, 2016). AHP at the modeling stage in this study continues the steps of Delphi process to calculate the relative weights of dimensions and factors. In the research design process with AHP, the hierarchical structure of factors should be first complete, Figure 2, and then the AHP 'paired comparison' questionnaire survey is designed. The retrieved AHP questionnaire survey has to satisfy the consistency index (CI) $\mathrm{CI} \leq 1$ and the consistency ratio (CR) $\mathrm{CR} \leq 0.1$ (Wu and Perng, 2017) to be effective. 


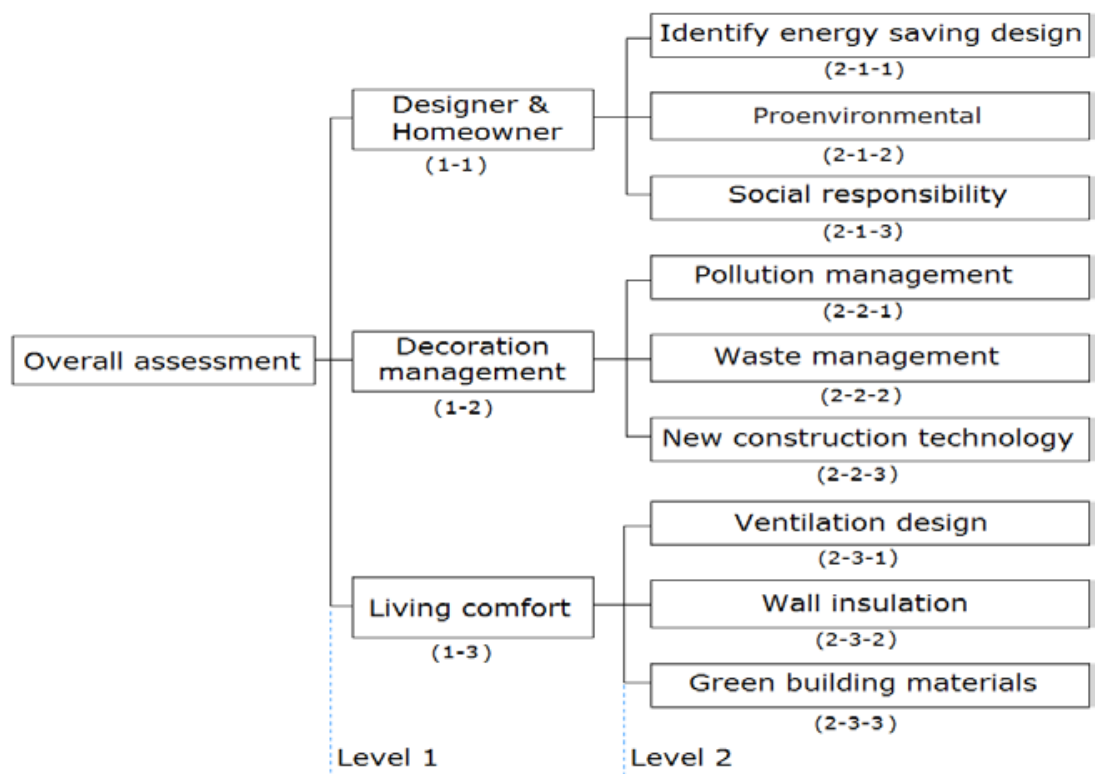

Figure 2. Diagram of Dimensions and Factors in Hierarchical Structure

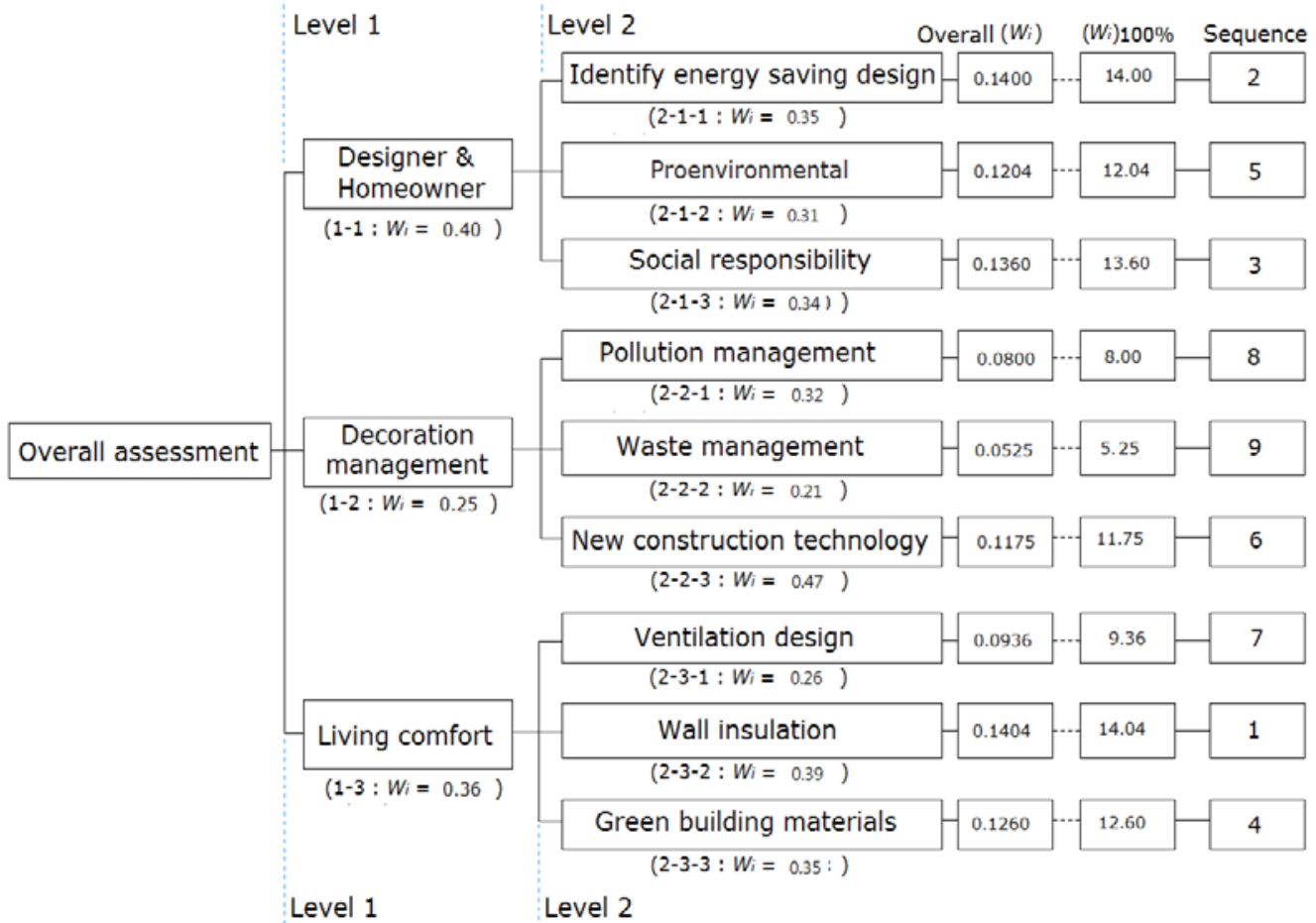

Figure 3. Relative Weights and Order of Factors

Total 96 copies of AHP questionnaire survey are distributed at the modeling stage, and 72 valid copies conforming to the AHP consistence test are retrieved for calculating the relative weights of factors with the AHP equation Table 1-Table 4. The calculation results are shown in Figure 3, in which the relative weights and order of factors are denoted with $W_{i}^{*} 100 \%$ for the convenient comparison. From Figure 3, relative importance of factors is ordered as wall insulation, agreement with energy saving design, social responsibility, green building materials, and pro-environment, where the social responsibility of environmental and the importance of energy saving design are explained. Besides, the use of green building materials and wall insulation are taken into account for the interior decoration in order to construct comfortable housing space. Furthermore, according to the relative importance order of factors in Figure 3, ventilation design does not remarkably contribute to space comfort, as most interviewees do not favor the interior space being affected by bad outdoor air quality and haze-fog in Taiwan. 
Table 1. Level 1 (Designers and House Owners, Decoration Management, Residence Comfort) Weight Calculation Level 1: Comparisons of 1-1, 1-2and 1-3

\begin{tabular}{|c|c|c|c|}
\hline Factors & $1-2$ & $1-2$ & $1-3$ \\
\hline $1-1$ & 1 & $1(1 / 5)$ & $1(1 / 2)$ \\
\hline $1-2$ & $5 / 6$ & 1 & $1 / 2$ \\
\hline $1-3$ & $2 / 3$ & 2 & 1 \\
\hline Weighting value & 0.40 & 0.25 & 0.36 \\
\hline
\end{tabular}

C.R. $=0.0811, \quad$ R.I. $=0.58, C l=0.0470$

Table 2. Level 2-1 (Agreement with Energy Saving Design, Pro-Environment, Social Responsibility) Weight Calculation Level 2: Comparisons of 2-2-1, 2-2-2 and 2-2-3

\begin{tabular}{cccc}
\hline Factors & $\mathbf{2 - 1 - 1}$ & $\mathbf{2 - 1 - 2}$ & $\mathbf{2 - 1 - 3}$ \\
\hline $2-1-1$ & 1 & $1(1 / 2)$ & $3 / 4$ \\
\hline $2-1-2$ & $2 / 3$ & 1 & $1(1 / 4)$ \\
\hline $2-1-3$ & $1(1 / 3)$ & $4 / 5$ & 1 \\
\hline Weighting value & 0.35 & 0.31 & 0.34
\end{tabular}

C.R. $=0.08105$, R.I. $=0.58, C l=0.04701$

Table 3. Level 2-2 (Pollution Management, Waste Management, New Construction Technology) Weight Calculation Level 2: Comparisons of 2-2-1, 2-2-2 and 2-2-3

\begin{tabular}{cccc}
\hline Level 2: Comparisons of $\mathbf{2 - 2 - 1}, \mathbf{2 - 2 - 2}$ and $\mathbf{2 - 2}-\mathbf{3}$ & $\mathbf{2 - 2 - 1}$ & $\mathbf{2 - 2 - 2}$ & $\mathbf{2 - 2 - 3}$ \\
\hline Factors & 1 & 2 & $1 / 2$ \\
\hline $2-2-1$ & $1 / 2$ & 1 & $3 / 5$ \\
\hline $2-2-2$ & 2 & $1(2 / 3)$ & 1 \\
\hline Weighting value & 0.32 & 0.21 & 0.47 \\
\hline
\end{tabular}

C.R. $=0.07413$, R.I. $=0.58, C l=0.04299$

Table 4. Level 2-3 (Ventilation Design, Thermal Insulation of Walls, Green Building Material) Weight Calculation Level 2: Comparisons of 2-3-1, 2-3-2 and 2-3-3

\begin{tabular}{cccc}
\hline Fevel 2: Comparisons of $\mathbf{2 - 3 - 1 ,} \mathbf{2 - 3 - 2}$ and $\mathbf{2 - 3 - 3}$ & $\mathbf{2 - 3 - 2}$ & $\mathbf{2 - 3 - 3}$ \\
\hline $2-3-1$ & 1 & $4 / 5$ & $3 / 5$ \\
\hline $2-3-2$ & $1(1 / 4)$ & 1 & $1(1 / 3)$ \\
\hline $2-3-3$ & $1(2 / 3)$ & $3 / 4$ & 1 \\
\hline Weighting value & 0.26 & 0.39 & 0.35 \\
\hline
\end{tabular}

C.R. $=0.03321$, R.I. $=0.58, C l=0.01926$

Utility theory and research design. Bernoulli explained the practical application value of Utility theory in 1738 (Luce, 1956), e.g. Testing the Effect of Risk Attitude (Farmer, 1993); and, Utility theory could also be utilized for understanding the value and monitoring the importance to many anthropological theories of economy (David and Pierson, 1998). Utility Theory is used in this study for developing the DAHP Expected Utility based decisionmaking analysis model, aiming to analyze the quantified value of factors in different scenarios. For this reason, the utility function of factors needs to be defined for the application of Utility Theory. Wu and Perng (2017) applied linear utility function, which was convenient for calculation and analyses, to establish the decision-making analysis model for evaluating the interior space comfort. Linear utility function is defined in this study as $f_{i}\left(y_{i}\right)=A \times y_{i}+$ $B$, as the maximum utility $f_{i}\left(y_{m}\right)=1$ and the threshold utility $f_{i}\left(y_{T}\right)=0$. The calculated linear utility function appears

$$
f_{i}\left(y_{i}\right)=\left[1 /\left(y_{m}-y_{T}\right)\right] \times y_{i}-y_{T} /\left(y_{m}-y_{T}\right)
$$

The quantified interval value needs to be further defined after defining utility function. Decision-makers' preference or practical situations could be the reference for the definition, including the highest quantified interval value $y_{\mathrm{H}}$, the lowest quantified interval value $y_{\mathrm{L}}$, and the $\left(y_{\mathrm{H}}-y_{\mathrm{L}}\right)$ interval value of factors. The utility function of factors could be further calculated after defining $y_{\mathrm{H}}, y_{\mathrm{L}}, y_{\mathrm{m}}$, and $y_{\mathrm{T}}$ of factors through the Delphi process, Table 5 . 
Table 5. Utility Function of Factors

\begin{tabular}{lccccc}
\hline Factors & $\boldsymbol{y}_{\boldsymbol{H}}$ & $\boldsymbol{y}_{\boldsymbol{L}}$ & $\boldsymbol{y}_{\boldsymbol{m}}$ & $\boldsymbol{y}_{\boldsymbol{T}}$ & Utility Function $\left(\boldsymbol{u}_{\boldsymbol{r}}\right)$ \\
\hline Identify Energy saving design & $100 \%$ & 0 & 100 & 30 & $f(y)=0.0142 y-0.429$ \\
\hline Pro-environment & $100 \%$ & 0 & 100 & 50 & $f(y)=0.02 y-1$ \\
\hline Social responsibility & $100 \%$ & 0 & 100 & 50 & $f(y)=0.02 y-1$ \\
\hline Pollution management & 0 & $100 \%$ & 0 & 30 & $f(y)=-0.0333 y+1$ \\
\hline Waste management & 0 & $100 \%$ & 0 & 30 & $f(y)=-0.0333 y+1$ \\
\hline New construction technology & 100 & 0 & 100 & 30 & $f(y)=0.0142 y-0.429$ \\
\hline Ventilation design & 0 & 60 & 0 & 20 & $f(y)=-0.05 y+1$ \\
\hline Wall insulation & $100 \%$ & 0 & 100 & 50 & $f(y)=0.02 y-1$ \\
\hline Green building materials & $100 \%$ & 0 & 100 & 50 & $f(y)=0.02 y-1$ \\
\hline
\end{tabular}

Table 6. Cases of Optimal Utility, Threshold Utility, and Lowest Utility

\begin{tabular}{|c|c|c|c|c|c|c|c|c|c|}
\hline \multirow{2}{*}{$\begin{array}{l}\text { Factors } \\
\left(W i^{\star} 100 \%\right) \\
\end{array}$} & \multicolumn{3}{|c|}{ Optimal utility } & \multicolumn{3}{|c|}{ Threshold utility } & \multicolumn{3}{|c|}{ Lowest utility } \\
\hline & $y_{m}$ & $f_{i}\left(y_{i}\right)$ & $\boldsymbol{f}_{\boldsymbol{i}}\left(\boldsymbol{y}_{\boldsymbol{i}}\right) * \boldsymbol{W i}$ & $y_{T}$ & $f_{i}\left(y_{i}\right)$ & $f_{i}\left(y_{i}\right) * W i$ & $y_{L}$ & $f_{i}\left(y_{i}\right)$ & $\boldsymbol{f}_{\boldsymbol{i}}\left(\boldsymbol{y}_{\boldsymbol{i}}\right) * W i$ \\
\hline 2-1-1 (14) & 100 & 1 & 14 & 30 & 0 & 0 & 0 & -0.429 & -6.00 \\
\hline $2-1-2(12.04)$ & 100 & 1 & 12.04 & 50 & 0 & 0 & 0 & $\begin{array}{ll}-1 \\
\end{array}$ & -12.04 \\
\hline $2-1-3(13.6)$ & 100 & 1 & 13.6 & 50 & 0 & 0 & 0 & -1 & -13.6 \\
\hline $2-2-1(8)$ & 0 & 1 & 8 & 30 & 0 & 0 & 100 & -2.33 & -18.64 \\
\hline $2-2-2(5.25)$ & 0 & 1 & 5.25 & 30 & 0 & 0 & 100 & -2.33 & -12.23 \\
\hline $2-2-3(11.75)$ & 100 & 1 & 11.75 & 30 & 0 & 0 & 0 & -0.429 & -5.04 \\
\hline $2-3-1(9.36)$ & 0 & 1 & 9.36 & 20 & 0 & 0 & 60 & -2 & -18.72 \\
\hline $2-3-2(14.04)$ & 100 & 1 & 14.04 & 50 & 0 & 0 & 0 & -1 & -14.04 \\
\hline $2-3-3(12.6)$ & 100 & 1 & 12.6 & 50 & 0 & 0 & 0 & -1 & -12.6 \\
\hline$\sum_{i=1}^{n} f_{i}\left(y_{i}\right) W_{i}$ & \multicolumn{3}{|c|}{100.64} & \multicolumn{3}{|c|}{0} & \multicolumn{3}{|c|}{-112.91} \\
\hline
\end{tabular}

DAHP expected utility function and model application. Expected Utility Theory presents the risk attitude tending to decision-makers' preference. By the combination of Delphi method, Analytical hierarchy process (AHP), and Utility theory, the development of the DAHP Expected Utility Function in this study presents high objectivity. Cohen indicated that the axioms need not be descriptive to be normative, and they need not be attractive to all decision makers for expected utility theory to be useful for some (Cohen, 1996). Housing Market Search Behavior and Expected Utility Theory: Measuring Preferences for Housing (Smith and Clark, 1982) is a case to establish the decision-making analysis model with Expected Utility Theory for housing issues. The Expected Utility Function based decision-making analysis model proposed in this study is the weighted AHP based on Delphi experts' knowledge that it presents practical application value.

A DAHP Expected utility based decision-making model for interior environmental decoration is deduced from the three approaches in this study that it presents qualitative and quantitative analysis functions. The calculation equation is shown as below.

DAHP Expected utility Function $=\sum_{i=1}^{n} f_{i}\left(y_{i}\right) W_{i}$

The optimal utility (the highest $y_{m}$ ), the threshold utility (the lowest $y_{\mathrm{T}}$ ), and the worse utility (the lowest $y_{\mathrm{L}}$ ), Table 6, of interior environmental decoration are taken as the examples to explain the application function of the decision-making model.

From Table 6, the three cases are calculated through the multi-attribute quantitative DAHP expected utility based decision-making model. The case of optimal utility shows the quantified evaluation value 100.64; the threshold utility case presents the quantified evaluation value 0 ; and, the quantified evaluation value appears 112.91 in the lowest utility case. From above calculations, the established DAHP Expected utility based decisionmaking model for interior environmental decoration presents the quantitative evaluation function.

\section{CONCLUSION}

Air quality in Taiwan is getting worse in past years. Although it is not as serious as in Beijing, China, the air quality in a half of the cities has influenced the citizens' respiratory tract hypersensitivity, and the air quality in central and southern areas shows bad effects on the health of local residents. Several demonstrations were jointly organized by several municipalities to protest the serious effect of air pollution on the citizens' health. Nevertheless, various industries, governmental management departments, and most citizens seemed to watch a street farce as most people did not have the social morality and social responsibility as environmental protectors did and less than a thousandth or a ten thousandth of the feeling of people with respiratory tract hypersensitivity about air pollution. Air pollution and environmental damage are the systematic and complicated problems in the entire society, as they 
involve in the demand for economic development, citizens' material desire in daily life, morality and responsibility, as well as cognition and education, which cannot be changed overnight. When the economy is fiercely competitive, the environmental pollution problem would approach the irreversible condition. Environmental protection and pollution control could merely be improved by the common concern of people.

With Delphi method, AHP, and Utility theory, the DAHP Expected utility based decision-making model for interior environmental decoration presents the characteristics of expert knowledge, relative weights of factors, and quantitative decision-making analysis. Besides, the model is convenient for the application and maintenance and shows high objectivity. In addition to evaluate the performance of a single interior decoration project, the model could also compare the performance among several interior decoration projects.

\section{SUGGESTION}

(1) In order to reduce environmental damage and pollution, it depends on the promotion of policies and the reinforcement of environmental universal education to cultivate the environmental protection awareness of industries and citizens. (2) When the investment in urban housing projects and the removal of interior space after the sale and transfer, the resource waste for redecoration, and the repeated environmental pollution could not be changed, interior designers should present the competence and duty of sustainable environmental design and play the role to educate house owners about environmental protection. (3) The green building regulations, green interior decoration, and use of green building materials in Taiwan merely restrict to government procurement and public construction, but not to the environmental interior decoration of private residences.

It is suggested that management departments should make strict regulations to effectively stop construction safety incident and improve interior decoration pollution. (1) Interior decoration regulations with both award and punishment could help guide private housing to the benign development of interior environmental decoration. The multi-attribute DAHP Expected utility based decision-making model for evaluating interior environmental decoration could be the reference for evaluating the award of private housing environmental decoration. (2) Interior designers' environmental protection awareness and the relative award and punishment should be promoted. The decision-making model constructed in this study could evaluate interior designers' competence of green design and green construction.

\section{REFERENCES}

Akasaka, H., Nimiya, H., \& Soga, K. (2002). Influence of heat island phenomenon on build heat load. Build. Serv. Eng. Res. Technol., 23(4), 269-278.

Battistoni, E., Colladon, A. F., Scarabotti, L., \& Schiraldi, M. M. (2013). Analytic hierarchy process for new product development. Int. J. Eng. Bus. Manag., 5, 1-8.

Bluyssen, P. M., de Richemont, S., Crump, D., Maupetit, F., Witterseh, T., \& Gadjos, P. (2010) Actions to reduce the impact of construction products on interior air: Outcomes of the European project healthy air. Interior Built Environ., 19(3), 327-339.

Brady, S. R. (2015). Utilizing and adapting the Delphi method for use in qualitative research. Int. J. Qual. Methods, 14(5), 1-6.

Chen, C. F. (2006) Applying the analytical hierarchy process (AHP) approach to convention site selection. J. Travel Res., 45(2), 167-174.

Cohen, B. C. (1996). Is expected utility theory normative for medical decision making? Med. Decis. Mak., 16(1), 1-6.

David, P., \& Pierson, M. M. (1998). Public affairs decision making in the U.S. air force: An application of multiattribute utility theory. J. Mass Communicat. Quart., 75(3), 606-626.

De Urioste-Stone, S., McLaughlin, W. J., \& Sanyal, N. (2006). Using the Delphi technique to identify topics for a protected area co-management capacity building programme. Int. J. Rural Manage., 2(2), 191-211.

Escaron, A. L., Chang Weir, R., Stanton, P., Vangala, S., Grogan, T. R., \& Clarke, R. M. (2016). Testing an adapted modified Delphi method synthesizing multiple stakeholder ratings of health care service effectiveness. Health Promo. Prac., 17(2), 217-225.

Farmer, T. A. (1993). Testing the effect of risk attitude on auditor judgments using multiattribute utility theory. J. Accoun. Audit. Finan., 8(1), 91-110.

Fokaides, P. A., Kylili, A., Nicolaou, L., \& Ioannou, B. (2016). The effect of soil sealing on the urban heat island phenomenon. Interior Built Environ., 25(7), 1136-1147.

Gerber, J. K., \& Yacoubian, G. S. (2002). An assessment of drug testing within the construction industry. J. Drug Educ., 32(1), 53-68. 
Hsueh, S. L. (2012). A fuzzy utility-based multi-criteria model for evaluating households' energy conservation performance: A Taiwanese case study. Energies, 5(8), 2818-2834.

Hsueh, S. L. (2015). Assessing the effectiveness of community-promoted environmental protection policy by using a Delphi-fuzzy method: A case study on solar power and plain afforestation in Taiwan. Renew. Sust. Ener. Rev., 49, 1286-1295.

Jacobs, J. M., \& Cairns, S. (2008). The modern touch: Interior design and modernisation in post-independence Singapore. Environ. Plan. A, 40, 572-595.

Kucukvar, M., Egilmez, G., \& Tatari, O. (2014). Evaluating environmental impacts of alternative construction waste management approaches using supply-chain-linked life-cycle analysis. Waste Manage. Res., 32(6), 500-508.

Lakshmana, C. M. (2014). Dynamics of urban growth, resource degradation and environmental pollution in million plus cities of India. Environ. Urban. ASIA, 5(1), 49-61.

Lee, S. E., \& Levermore, G. J. (2012). Simulating urban heat island effect with climate change on a Manchester house. Build. Serv. Eng. Res. Technol., 34(2), 203-221.

Levermore, G. J., \& Parkinson, J. B. (2016). An empirical model for the urban heat island intensity for a site in Manchester. Build. Serv. Eng. Res. Technol., 38(1), 21-31.

Li, L., Tang, D., Kong, Y., Yang, Y., \& Liu, D. (2016). Spatial analysis of haze-fog pollution in China. Ener. Environ., 27(6-7), 726-740.

Liefner, I., \& Jessberger, S. (2016). The use of the analytic hierarchy process as a method of comparing innovation across regions: The examples of the equipment manufacturing industries of Shanghai and Xiamen, China. Environ. Plan. A, 48(6), 1188-1208.

Luce, R. D. (1956). Semiorders and a theory of utility discrimination. Econometrica, 4, 178-191.

Novakowski, N., \& Wellar, B. (2009). Using the Delphi technique in normative planning research: Methodological design considerations. Environ. Plan. A, 40(6), 1485-1500.

Ojeda-Benítez, S., Aguilar-Virgen, Q., Taboada-González, P., \& Cruz-Sotelo, S. E. (2013). Household hazardous wastes as a potential source of pollution: A generation study. Waste Manage. Res., 31(12), 1279-1284.

Plassmann, F., \& Khanna, N. (2006). Household income and pollution-implications for the debate about the environmental Kuznets curve hypothesis. J. Environ. Dev., 15(1), 22-41.

Poortinga, W., Steg, L., \& Vlek, C. (2004). Values, environment concern, and environment behavior: A study into household energy use. Environ. Behav., 36(1), 70-93.

Sellappan, E., \& Janakiraman, K. (2014). Environmental noise from construction site power systems and its mitigation. Noise Vibrat. World., 45(3), 14-20.

Smith, T. R., \& Clark, W. A. V. (1982). Housing market search behavior and expected utility theory: 1. measuring preferences for housing. Environ. Plan. A, 14(5), 681-698.

Taiwan Environmental Protection Administration. (2017). Statistics of total greenhouse gas emission. Retrieved from http:/ / www.epa.gov.tw/ct.asp?xItem $=10052 \& c t N o d e=31352 \& \mathrm{mp}=$ epa

White, W. C., \& Kuehl, M. H. (2002). The role of contamination textiles in interior environment pollution. J. Indus. Text., 32(1), 23-43.

Wu, W. C., \& Perng, Y. H. (2017). AHP-utility based model for evaluating the comfort of housing: A case study of Taiwan. Appl. Ecol. Environ. Res., 15(2), 133-144.

Yun, J. S. (2004). Model for measuring Korean administrative corruption: Focusing on the application of the AHP method. Int. Area Stud. Rev., 7(1), 221-245.

Zheng, Q., Lee, D., Lee, S., Kim, J. T., \& Kim, S. (2011). A health performance evaluation model of apartment building interior air quality. Interior Built Environ., 20(1), 26-35.

\section{http://www.ejmste.com}

